\title{
Mission impossible: the quest for medical school
}

$\mathrm{L}$

ike many other would-be physicians, my journey into medicine started full of energy and hope. In the face of a very public doctor shortage, I thought surely Canada would do everything to retain its best and brightest. Applying to Canadian medical schools quickly changed my opinions on this.

Ontario is one of, if not the most, difficult places to get into medical school in North America; entry is especially difficult if you are from the greater Toronto area.

I cannot tell you how many of my colleagues with near-perfect grades, extensive community involvement and great Medical College Admission Test scores were unable to get in.

The lucky few get in somewhere in Canada or the United States, like myself, now enrolled in Jefferson Medical College at Thomas Jefferson University in Philadelphia, Pennsylvania. The rest end up mainly at schools in the Caribbean, Australia or Ireland. Or turn away from medicine.

Why is that?

The first thing that jumps into my mind is the acceptance criteria for the universities of Toronto and McMaster, the two schools in the greater Toronto area. Neither gives preference to students from the area. Yet, most other schools have set aside spaces and favour applicants from their own geographic region. For example, the University of Ottawa, Northern Ontario School of Medicine and the University of Western Ontario all treat "local" applicants preferentially.

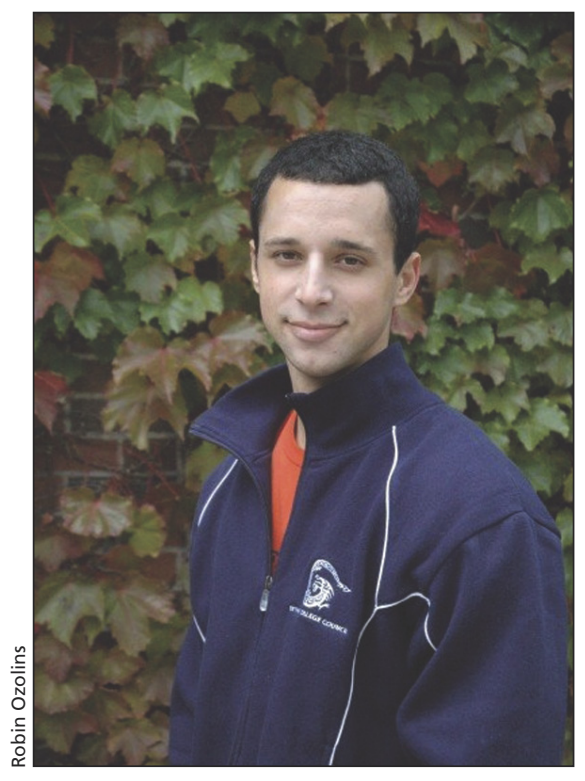

Jefferson Medical College student Joel Warsh says preferential treatment disadvantages some applicants to Canadian medical schools.

It seems unfair that someone who grew up two to three hours down the 401 can get an interview with lower grades and MCAT scores. We are all from Ontario and should be treated as equals, shouldn't we?

As well, applying to out-of-province schools is even more problematic, as few spaces are available for us "foreign" applicants.

I am sensitive to the needs of underserved communities for whom these regional acceptance practices were created. The purpose of extending preferential recruitment to local applicants is, of course, to encourage doctors to stay and practise in the area.

However, the end result remains: Many qualified, motivated, enthusiastic and otherwise-deserving students are being turned away from medical schools simply because of where they live.

What is the answer?

It seems logical that another medical school should be built in the greater Toronto area and and that more spaces for out-of-province students should be created across the country.

Our current admission policies are losing students with a passion, drive and commitment to medicine - not because they are unqualified, but because we haven't created space for them. We are losing some of our best students to schools in other countries, which is an admission that no Canadian should prefer. - Joel Warsh, Kingston, Ont., with thanks to John Fralick and Ian Cromwell for their input

DOI:10.1503/cmaj.109-3041

CMAJ invites contributions to "Dispatchs from the medical front," in which physicians and other health care providers offer eyewitness glimpses of medical frontiers, whether defined by location or intervention. Submissions, which must run a maximum 700 words, should be forwarded to:wayne.kondro@cmaj.ca 